\section{Principia}

\section{Microscopica}

GrahamDunn

Light and Electron Microscopy. By Elizabeth $M$. Slayter and Henry $S$. Slayter. Cambridge University Press: 1993. Pp. 256. £35, \$64.95 (hbk); $£ 14.95, \$ 27.95(p b k)$.

WHAT a refreshing change to open a new book on microscopy that is not only packed with information on recent advances in the field but also contains a broad foundation of theoretical principles. The volume is slim, and it is hard to believe that the wide range of material is covered in such depth until one realizes what has been left out: the usual dreary rules-of-thumb for operating microscopes that might as well be describing masonic rituals for all the explanation - or intellectual stimulation - that they offer. In fact, I opened the book with pleasurable anticipation because Elizabeth Slayter was already familiar to me as the author of my well-thumbed copy of Optical Methods in Biology (Wiley, 1970). Her untimely death in 1987 is a sad loss to light microscopy. Her coauthor here, also her husband, attributes "any clarity, thoroughness, or felicitous style" to her; but the consistent expression of these qualities suggests he is too modest.

Although the book is not targeted exclusively at biologists, it is assumed that it "will appeal especially to graduate students and researchers in the biomedical sciences". But because most biologists are not proficient in the theory of vector fields, it may seem risky to kick off with anything as intimidating as Maxwell's equations. Is this the fabled pons asinorum that confronts us or are we being invited simply to marvel at the cornerstone of modern optical theory? Probably the latter, because whenever mathematical notation is introduced elsewhere, the concepts are explained verbally in the best tradition of Richard Feynman's Lectures on Physics. Most research biologists should be able to cope with the text but there are undoubtedly some bridges that mathematical asses will find difficult to cross. Those with an incurable terror of equations should resign themselves to the fact that microscopy, in theory if not in practice, is essentially a physicomathematical subject.

Having negotiated Maxwell's equations by whatever means at his or her disposal, the reader is coaxed through the principles of microscope optics and the Fourier theory of image formation. I envy those who first encounter these topics here, for the clouds of incomprehension are swept away so deftly that enlightenment may creep up on them unawares. It will probably begin to dawn half way through the book, in a chapter disarmingly called "The Light Microscope", when the familiar features of design and operation of the microscope will suddenly be seen in a new light - the light of understanding.

The remaining chapters largely describe how the principles are applied in a wide variety of microscope designs. Not only are the usual forms of light and electron microscopy covered comprehensively, with special emphasis on biological applications, but novel instruments such as the total-internal-reflection microscope are also described briefly. Indeed, the book explores regions well beyond the bounds set by its title, devoting a whole chapter to X-ray microscopy. Another chapter presents a veritable menagerie of such exotic species as field-ion, neutron, photoelectron, scanning tunnelling, atomic force, nuclear magnetic resonance and acoustic microscopes. The final chap- ter concerns photography, seemingly mundane after all this high technology, but even this familiar topic is treated with a deep insight into underlying principles.

Microscopy is currently enjoying a renaissance as new approaches to image formation, advances in digital image processing and developments in nanotechnology take it into areas of application hitherto undreamed of. Even routine forms of microscopy are now changing rapidly and there is greater need than ever for research biologists to understand the function of their instruments, if only to interpret the image that they produce. Although there is no easy route to understanding, this book will make the effort rewarding, and I suspect that it will soon find its way onto the shelves of microscopists who take their craft seriously.

Graham Dunn is in the MRC Muscle and Cell Motility Unit, King's College London, 26-29 Drury Lane, London WC2B 5RL, UK.

\title{
Responses to change
}

\section{J. John Lowe}

Quaternary Environments. By M. A. J. Williams, D. L. Dunkerley, P. de Deckker, A. P. Kershaw and T. Stokes. Edward Arnold: 1993. Pp. 329. £16.95 (pbk).

SEVERAL textbooks on Quaternary geology or environmental history have appeared in recent years, and the authors of each have faced the same dilemma: how to get across the breadth and scope of this vast (and still growing) subject within the confines of a standard text. The answer, of course, is to avoid any attempt to 'cover' the subject, and instead to concentrate on key concepts, illustrate the astonishing rapidity and complexity of environmental changes during the Quaternary period, and exemplify the multidisciplinary nature of current research in the field. Authors of previous texts have attempted this with varying degrees of success. This new publication, written by teachers and researchers of the Australian National University, Monash University and the University of Adelaide, is one of the more successful efforts.

As an introductory text for undergraduate students, it has a very wide brief. It aims to examine global environmental fluctuations of the past 2 million years, establish the basis of some of the important methods of analysis used to reconstruct them, and consider the ways in which organisms (including humans) have responded to the fluctuations. It is inevitable, then, that much of the material lacks detailed explanation and that some important issues are oversimplified. But what the volume does do is to provide students with a well-structured platform for understanding the pivotal role of Quaternary studies in science today.

The importance of understanding oceanic circulation, rapid environmental changes in today's desert regions, the history of Quaternary glaciations, the kaleidoscopic patterns of adjustment in global flora and fauna, theories of human origins and migrations, atmospheric circulation processes, and a knowledge of Quaternary environmental history as a necessary framework for assessing impacts of future climatic change - all of these are neatly introduced without a heavy terminological armour.

Particular attractions of the book are the treatments of topics that are dealt with too briefly or not at all in other texts. Thus the 'prelude' provided of global changes during the Tertiary, the detailed examination of evidence from desert regions and lakes in low latitudes, the useful models of oceanic and atmospheric processes and the succinct introduction to human history are all very welcome. The Southern Hemisphere perspective is also a bonus, and serves to remind northern readers that the North Atlantic is only a cog albeit a large one - in an intricate global machine.

Overall, this is a lucid and lively book with compelling messages. It illustrates why the Quaternary period offers such a popular and vital forum for Earth scientists today.

J. John Lowe is in the Centre for Quaternary Research, Royal Holloway, University of London, Egham, Surrey TW2O OEX, UK. 